\title{
Mechanisms of Sintering of Macroporous Hydroxyapatite Adsorbents
}

\author{
A. Nzihou" and S. Bailliez \\ Ecoles des Mines diAlbi-Carmaux - Centre Energetique et Environnement \\ Laboratoire de Genie des Procedes des Solides Divises, UMR CNRS 2392 \\ Campus Jarlard,81013 'ALBI Cedex 09, France
}

Received October 28, 2002

\begin{abstract}
The behaviour during calcination of two hydroxyapatites (HAP), one calcium deficient and the second with calcium excess, was investigated. A structural change in terms of the crystallization, combined with significant decreases of the specific surface area by sintering process, was observed. This process begins near $600^{\circ} \mathrm{C}$ and reaches a maximum near $900^{\circ} \mathrm{C}$. The decay in specific surface area observed is described accurately by an empirical equation of the form $\frac{d S}{d t}=-B^{\prime}(T) S^{h}$ where $S$ is the specific surface area, $t$ is the time, $b$ and $B^{\prime}(T)$ are respectively the reaction order and the constant rate which depends on the calcination temperature. These constants vary swiftly with changing temperature, suggesting that the mechanism of the sintering may change with the temperature. The results for the two macroporous HAPs are compared and discussed in terms of various possible mechanisms of materials transport involved in the sintering process.
\end{abstract}

Key words: macroporous hydroxyapatite, kinetics, structural change, sintering, diffusion process

\footnotetext{
" Corresponding author. Tel: 00335634932 22,
} fax: 00335634930 99; e-mail: nzihou@enstimac.fr

\section{INTRODUCTION}

Hydroxyapatite (HAP) which is an insoluble calcium phosphate mineral of composition $\mathrm{Ca}_{10}\left(\mathrm{PO}_{4}\right)_{6}(\mathrm{OH})_{2}$ has been used as a cation exchanger and adsorbent in wastewater treatment and has a very high capacity for removing divalent heavy metal ions from water and liquid waste /1-5/. HAP can accept a series of cationic and anionic substitutions $/ 6-8 /$ in its structure. In consequence, it has been proposed for the removal of heavy metals from soils and wastewater $19,10 \%$. Thus, the understanding of the effect of these substitutions on the HAP structure and properties (dissolution, crystallisation, surface reactivity and thermal behaviour) has motivated many fundamental works in recent years. Three types of reactions may control the retention of heavy metals by the HAP matrix: surface adsorption, cation exchange (substitution) or precipitation.

Some of the mechanisms described above are reversible depending on the $\mathrm{pH}$ conditions, and the trapped metal can be leached and cause pollution when the residues are landfilled or reused. The insolubilisation of hydroxyapatite absorbents containing heavy metal is obtained by calcination. This leads to 
significant textural changes, mainly concerning specific surface area, porosity, particle size, density and crystallisation of matrices. Other phenomena observed during the calcination are structural changes due to crystallisation of the matrices and formation of neoadsorbents when heavy metals are incorporated /11-13/.

The results presented in this paper deal with the mechanism of sintering during the calcination of two non-stoichiometric hydroxyapatites, one containing tricalcium phosphates and the second some carbonates. This first step is necessary to later compare the behaviour of hydroxyapatite that is matrix doped and free of metal ions during the sintering process, and then to understand the mechanism of the stabilisation of the heavy metal in a hydroxyapatite matrix. The processes followed are the crystallisation process and the specific surface area.

The structural changes due to the combined effects of sintering and the reaction of hydroxyapatite formation are used to express the kinetics of the sintering of hydroxyapatite. This paper presents a review of the literature on sintering, and a detailed experimental study of the change in structural properties caused by sintering. The aim is to understand and compare the structural changes and mechanisms in terms of the specific surface area. The two hydroxyapatites have different initial specific surface area and different compositions in term of $\mathrm{Ca} / \mathrm{P}$ ratio, which is 1.6004 for the first one and 1.7275 for the second, in comparison with the stoichiometric hydroxyapatite for which the $\mathrm{Ca} / \mathrm{P}$ ratio is 1.6667 . The results are compared with literature models describing the sintering process by specific surface area reduction.

\subsection{Theoretical consideration}

Several authors have proposed such models to describe the sintering process. Beginning with Kuczynski's study of neck growth between a sphere and a plate and between two spheres in $1949 / 14 /$, and continuing with the work of, among others, Kingery and Berg $/ 15 /$ on diffusion based two-sphere sintering models and Burke $/ 16 /$ on pore pinning of grain boundaries, a great deal of progress has been made in understanding the different mechanisms of mass transport and their effects on densification and coarsening during the sintering. Coble $/ 17,18 /$ formulated bulk diffusion models for sintering by modelling the microstructure as one of three simple geometries, based on the concept that the sintering process could be divided into three stages corresponding to changes in topology. This approach has more recently been used by Ashby /19/ and others /20,21/ to develop sintering maps that compile all the information involving density as a function of time and pressure by summing the contributions of all the different mechanisms of materials transport. This method, characterised by simplified geometric models of the microstructure, has been effective in indicating the dominant transport mechanisms. Arzt /22/ extended this approach by proposing a method, based on shrinking Voronoi cells, by which the effect of increasing particle coordination number could be modeled.

Sintering is traditionally viewed in terms of three distinct stages; most modelling efforts focus on a specific, idealised geometry for only one of the stages 114,15,23-25/. Two problems arise with this approach. First, an idealised geometry must be assumed in order to calculate diffusional flow analytically; this limits the applicability of such models in real situations. Secondly, this approach does not allow consideration of the entire sintering process from beginning to end. It is therefore desirable to derive a model that describes the entire sintering process.

Several authors have proposed such models. Wang and Raj $/ 25 /$ used a generalised sintering equation in their study for sintering activation energies: they did not, however discuss its derivations or implications. Zhao and Harmer /26/ derived and applied a simplified sintering model to final-stage sintering of idealised alumina compacts. Chu et al. $127 /$ proposed another general model including simultaneous coarsening and densification.

In principle, a single equation can be derived which describes the sintering by densification through all stages of sintering, if (a) the kinetics of mass transport which lead to densification can be expressed mathematically and (b) the microstructure can be quantified to embody both its tendency to generate mass flows which contribute to densification, and the 
efficiency at which such flows are converted into shr..'kage. To satisfy condition (a), it will be assumed at the outset that only capillarity-induced diffusional mass flows contribute to densification. Therefore, the challenge in developing a combined-stage sintering model is to find a method for correctly quantifying the complex changes in microstructure which occur during sintering.

However, we can observe that most theories of the sintering process of solids subjected to high temperature and/or pre $\_$su.e (as in hot and cold compaction) deduce the shrinkage from the linear densification between two spherical particles in a regular packing. Nevertheless, this approach neglects the peculiarities arising from the fact that the particle structure is never regular and changes continually during densification. As the average particle distance decreases, the particles are squeezed together and form contact areas. During this process the average number of contacts per particle, which is called the coordination number, increases steadily $122 \%$.

\subsection{Surface area reduction models}

We mentioned in this paper some of the reports in the literature describing the surface area reduction during sintering. Nicholson $128 /$ described the relationship between surface area, time, and temperature as follows:

$$
\frac{d S}{d t}=-K_{2}(T)\left(S-S_{f}\right)
$$

This relationship was verified with the sintering data of magnesium oxide and iron oxide. Caillet and Harisson 129/ used this equation to correlate their $\mathrm{ZnO}-\mathrm{ZnS}$ sintering data. The temperature dependence $k_{2}(T)$ was expressed by an Arrhenius equation and the asymptotic surface area at the specific sintering temperature, $S_{\mathrm{f}}$ was determined experimentally. $K_{2}(T)$ is the sintering rate constant.

Nicholson $/ 28 /$ has shown that the specific surface area of a non-reacting, sintering solid varies with time according to the equation:

$$
\frac{S(t)-S_{e}}{S_{n}-S_{e}}-e^{-k_{j} t}
$$

Both the sintering rate constant, $\mathrm{k}_{1}$ and the equilibrium surface area, $S_{e}$, are functions of temperature and must be determined experimentally. Ranade and Harrison 130/ related specific surface area and grain radius by assuming that all the grains are non-porous spheres having equal radius $r$, defined as follows:

$$
r=\frac{3}{S \rho}
$$

where $\rho$ is the density of the particle and $S$, the specific surface area.

German $131 /$ postulated that, at the intermediate stage of sintering, the surface area reduction kinetics followed a power law equation

$$
\frac{d S}{d t}=-B^{\prime}(T) S^{h}
$$

The functional relationship of $B^{\prime}(T)$ with temperature was not discussed; the exponent $b$, the reaction order, was reported to be between 2.6 and 3.3 for various materials. Schlaffler et al. /32/ and Caillet and Harrison 29/ also used a power law equation to describe the surface area variation of silica-alumina catalysts in steam at temperatures from $478^{\circ} \mathrm{C}$ to $863^{\circ} \mathrm{C}$. Reported values of the exponent, $b$, ranged from 9.1 at the lower temperature to 3.8 at the higher.

Compared to neck size and shrinkage measurements, surface area offers several advantages as a sinteringprocess monitor because the surface area reductions accompany all sintering mechanisms, and it is an easily measurable quantity $131 \%$. Also, the surface area is affected very little by the rearrangement events of the initial stage of sintering. Such measurements average many neck growth events without tedious neck size measurements. Surface area as a sintering parameter is most appropriate to fine particles, a size region where it is difficult to measure neck diameter. 


\section{MATERIALS AND METHODS}

\subsection{Synthesis of hydroxyapatite (HAP) powder}

The experiments were carried out with two hydroxyapatites synthesized at room temperature by precipitation in solution $133 /$. The first one, $\mathrm{HAP}_{\mathrm{TCP}}$, was obtained according to the reaction (5) between calcium chloride $\left(\mathrm{CaCl}_{2} .2 \mathrm{H}_{2} \mathrm{O}\right.$ from ALDRICH, $98 \%$ minimum), and phosphoric acid $\left(\mathrm{H}_{3} \mathrm{PO}_{4}\right.$ from PROLABO, $85 \%$ minimum). The $\mathrm{pH}$ was adjusted to 7 8 with caustic soda solution. The temperature of the solution was maintained usually at $298 \mathrm{~K}$. The second hydroxyapatite, $\mathrm{HAP}_{\mathrm{CaO}}$, was prepared by mixing calcium nitrate $\left(\mathrm{Ca}\left(\mathrm{NO}_{3}\right)_{2}\right.$ from NORSKHYDRO) and ammonium phosphate $\left(\left(\mathrm{NH}_{4}\right)_{2} \mathrm{HPO}_{4}\right.$ from NORSKHYDRO) at $100^{\circ} \mathrm{C}$ and the $\mathrm{pH}$ was adjusted to $7-8$ with a $20 \%$ ammonia solution according to reaction (6):

$$
\begin{aligned}
& 10 \mathrm{CaCl}_{2}+6 \mathrm{H}_{3} \mathrm{PO}_{4}+20 \mathrm{NaOH} \rightarrow \mathrm{Ca}_{10}\left(\mathrm{PO}_{4}\right)_{6}(\mathrm{OH})_{2}+ \\
& 20 \mathrm{NaCl}+18 \mathrm{H}_{2} \mathrm{O} \\
& 10 \mathrm{Ca}\left(\mathrm{NO}_{3}\right)_{2}+6\left(\mathrm{NH}_{4}\right)_{2} \mathrm{HPO}_{4}+8 \mathrm{NH}_{4} \mathrm{OH} \rightarrow \\
& \mathrm{Ca}_{10}\left(\mathrm{PO}_{4}\right)_{6}(\mathrm{OH})_{2}+20 \mathrm{NH}_{4} \mathrm{NO}_{3}+6 \mathrm{H}_{2} \mathrm{O}
\end{aligned}
$$

\subsection{Characterisation of materials}

The structure and the composition of the dried particles was identified and quantified by X-ray powder diffractometry (Siemens D5000). XRD measurements were carried out with $\mathrm{CuK}_{\alpha}$ radiation generated at 40 $\mathrm{kV}$ and $40 \mathrm{~mA}$, in the $3^{\circ}<2 \theta<60^{\circ}$ range at a scan speed of $2^{\circ} \mathrm{C} / \mathrm{min}$. The phases present were determined by comparing the patterns with JCPDS standards.

The specific surface area of the particles was determined by nitrogen adsorption using a BET method (MICROMERETICS Gemini Vacprep 061). The value obtained for the dried particles was $38 \mathrm{~m}^{2} / \mathrm{g}$ for $\mathrm{HAP}_{\mathrm{TCP}}$ and $104 \mathrm{~m}^{2} / \mathrm{g}$ for $\mathrm{HAP}_{\mathrm{CaO}}$

The bulk density of the powder was measured by helium pycnometry (Micromeritics, Accupyc 1330) and the results obtained are: $d_{H A T_{T C r}}=2.97 \mathrm{~g} / \mathrm{cm}^{3}$, and $d_{H A P_{C O S}}=2.79 \mathrm{~g} / \mathrm{cm}^{3}$
Pore-size distributions were measured on the powder specimen via mercury intrusion porosimetry (Model Autopore III, Micromeritics Instrument), using a $3 \mathrm{ml}$ glass cell. The pore-size distribution follows the relation:

$$
d=\frac{4 \gamma \cos \theta}{P}
$$

where $d$ is the pore diameter, $\gamma$ the surface tension, $\theta$ the contact angle, and $\mathrm{P}$ the mercury pressure. The pore diameter was calculated from the pressure applied to the powder, and the total open porosity was calculated from the mercury intrusion volume.

The particle size distribution of the powder was determined with a MALVERN laser mastersizer Hydro 2000. The particles were placed in an ethanol suspension shaken by ultrasound. The mean sizes of $11 \mu \mathrm{m}$ for $\mathrm{HAP}_{\mathrm{TCP}}$ and of $18 \mu \mathrm{m}$ for $\mathrm{HAP}_{\mathrm{CaO}}$ were obtained.

Calcination experiments were carried out in a $2 \mathrm{~L}$ furnace. The heating program was: heating rate of $10^{\circ} \mathrm{C} / \mathrm{min}$ from $30^{\circ} \mathrm{C}$ to the chosen isotherm temperature and the isothermal stages varying from 0 to 120 minutes. The samples were placed in an alumina crucible and heated up to the selected temperature under flowing air, then held for the same time and cooled at the same rate with a maximum heating temperature of $1600^{\circ} \mathrm{C}$.

\section{RESULTS AND DISCUSSION}

\subsection{Characteristics of the starting powders}

The characteristics of the powder are presented in Table 1. The ACP powder synthesized has a macroporous structure and the particle size is small.

\subsection{Effect of thermal conditions on the structure of amorphous calcium phosphate (ACP)}

The XRD patterns of Figure 1 show the presence of an amorphous phase at temperatures below $500^{\circ} \mathrm{C}$. The 
Table 1

Initial parameters of the amorphous calcium phosphate

\begin{tabular}{|c|c|c|c|c|}
\hline \multicolumn{3}{|c|}{ Powder } & $\mathrm{HAP}_{\mathrm{CaO}}$ & HAP $_{\text {TCP }}$ \\
\hline \multicolumn{3}{|c|}{ Specific surface area $\left(\mathrm{m}^{2} / \mathrm{g}\right)$} & 104 & 38 \\
\hline \multicolumn{3}{|c|}{ Density $\left(\mathrm{g} / \mathrm{cm}^{3}\right)$} & 2.8 & 2.97 \\
\hline \multicolumn{3}{|c|}{ Particle size $(\mu \mathrm{m})$} & 18 & 11 \\
\hline \multicolumn{3}{|c|}{ Porosity $\%$} & 47.4 & 49 \\
\hline \multirow{6}{*}{ 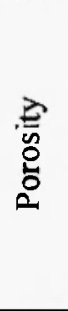 } & \multirow{2}{*}{$\begin{array}{c}\text { Micropore } \\
<20 \AA\end{array}$} & Volume $\left(\mathrm{cm}^{3} / \mathrm{g}\right)$ & - & - \\
\hline & & Pore size $(\AA)$ & - & - \\
\hline & \multirow{2}{*}{$\begin{array}{l}\text { Mesopore } \\
20-500 \AA \\
\end{array}$} & Volume $\left(\mathrm{cm}^{3} / \mathrm{g}\right)$ & 0.09 & $=$ \\
\hline & & Pore size $(\AA)$ & 142 & - \\
\hline & \multirow{2}{*}{$\begin{array}{c}\text { Macropore } \\
>500 \AA\end{array}$} & Volume $\left(\mathrm{cm}^{3} / \mathrm{g}\right)$ & 0.23 & 0.31 \\
\hline & & Pore size $(\AA)$ & 14700 & $459-648$ \\
\hline
\end{tabular}

sample heated at temperatures greater than $600^{\circ} \mathrm{C}$ exhibited broad peaks on an apatite phase. When the temperature was increased, the apatitic peaks became sharper, because of crystal growth. Each pattern has hydroxyapatite as the major phase component. However, traces and significant amounts of other phases were detected. These phases are essentially composed by intermediate calcium phosphates between ACP and HAP. The apatite structure prevailed until the temperature reached $1200^{\circ} \mathrm{C}$, when it decomposed partially into tetracalcium phosphate $\left(\mathrm{Ca}_{4}\left(\mathrm{PO}_{4}\right)_{2} \mathrm{O}, \mathrm{TTCP}\right)$ and $\alpha$-tricalcium phosphate

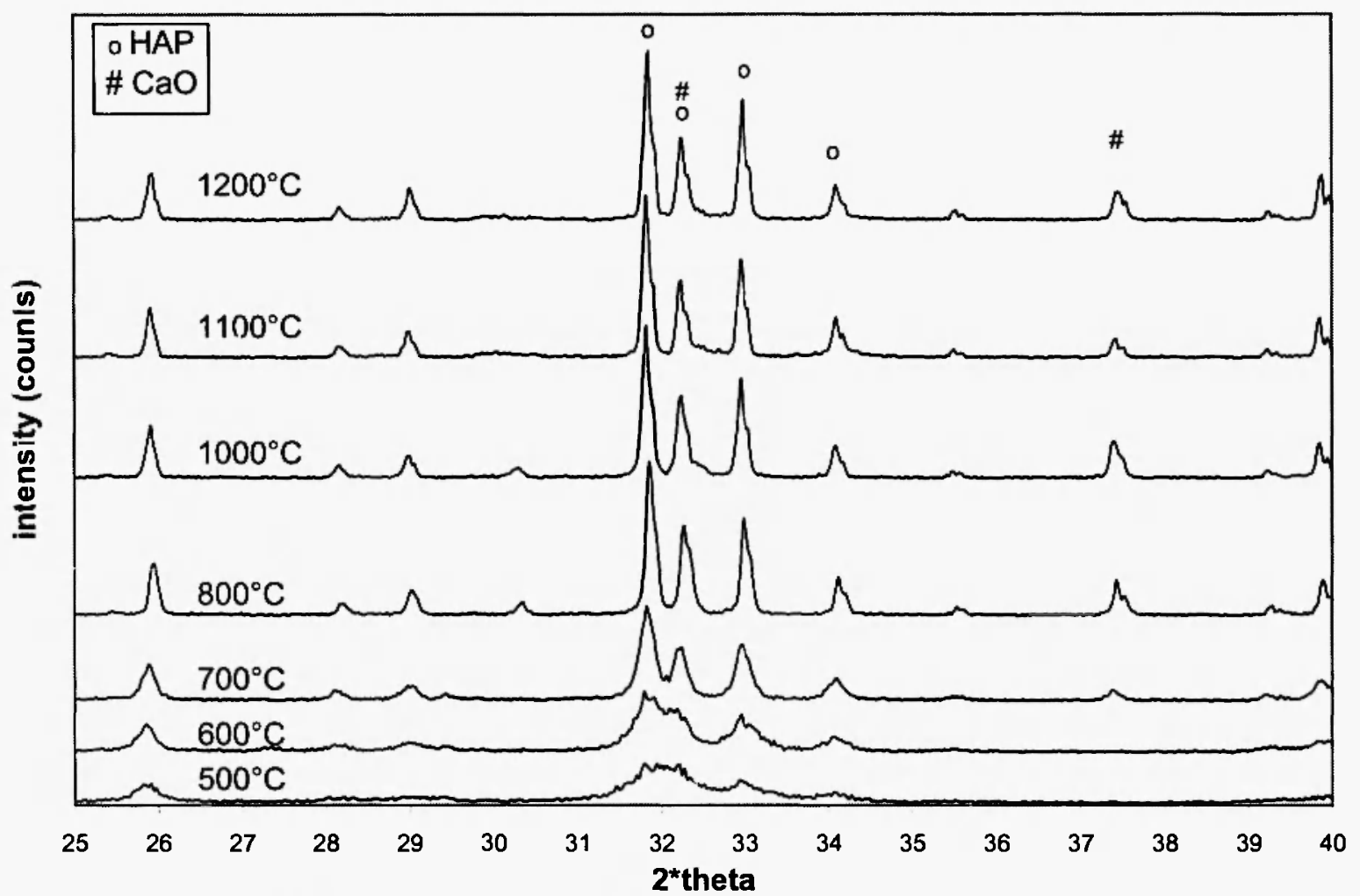

Fig. 1: XRD pattern of $\mathrm{HAP}_{\mathrm{CaO}}$ versus the calcination temperature. 
$\left(\mathrm{Ca}_{3}\left(\mathrm{PO}_{4}\right)_{2}, \alpha-T C P\right)$.

The XRD references were obtained according to the AFNOR standard /34/. The two hydroxyapatites were then calcined for 15 hours at $1000^{\circ} \mathrm{C}$. The calcination allows the crystallization of the particles by comparison with the dried particles as shown in Figure 2 for $\mathrm{HAP}_{\mathrm{TCP}}$ and in Fig. 3 for $\mathrm{HAP}_{\mathrm{CaO} \mathrm{O}}$. Approximately $39 \mathrm{wt} \%$ of tricalcium phosphate $\left(\mathrm{Ca}_{3}\left(\mathrm{PO}_{4}\right)_{2}\right)$ was present in HAP $_{\text {TCP }}$ and about $2 \mathrm{wt} \%$ of $\mathrm{CaO}$ was detected in HAP $_{\mathrm{CaO}}$. These XRD patterns of the calcined particles help to conclude that $\mathrm{HAP}_{\mathrm{TCP}}$ is an $\mathrm{ACP}$ with a $\mathrm{Ca} / \mathrm{P}$ ratio of 1.6004 which becomes a mixture of hydroxyapatite and tricalcium phosphate (TCP) at high temperature and $\mathrm{HAP}_{\mathrm{CaO}}$ is an $\mathrm{ACP}$ with a $\mathrm{Ca} / \mathrm{P}$ ratio of 1.7275 which becomes a mixture of lime $(\mathrm{CaO})$ and hydroxyapatite at high temperature. As the $\mathrm{Ca} / \mathrm{P}$ ratio of stoichiometric hydroxyapatite is 1.6667 , the first, HAP $_{\text {TCP }}$, is a calcium deficient hydroxyapatite and the second, $\mathrm{HAP}_{\mathrm{CaO}}$, is a hydroxyapatite with a calcium excess.

The specific surface area (Fig. 4) is constant and equal to that of the initial particles $\left(38 \mathrm{~m}^{2} / \mathrm{g}\right)$. In this domain, the structure of the particles does not change significantly.

\subsection{Sintering kinetic Study}

All samples were analysed by the method in order to determine the specific surface area as a function of time and temperature for the 2 hydroxyapatites investigated (Fig. 4). Three models from the literature (Table 2) were used to correlate the experimental data showing the decrease of specific surface area. The principles of these models were related in section 1 of this paper

The equations of Table 2 were solved using a MATLAB software. According to the model, the HAP shell is divided into multiple layers of subgrains depending on the time interval in which they are formed. The surface area of each subgrain layer is calculated by simultaneously solving the equations of Table 2 at each time step. The minimising function is represented as follows:

$$
f(x)=\sum_{i=1}^{n+x p}\left[S_{i}^{c a l}(x)-S_{i}^{\exp }\right]^{2}
$$

where $S_{i}^{c a l}$ is the calculated specific surface area at $\mathrm{i}$ step and $S^{\exp }$, the experimental specific surface area considered. In this study the value of initial specific

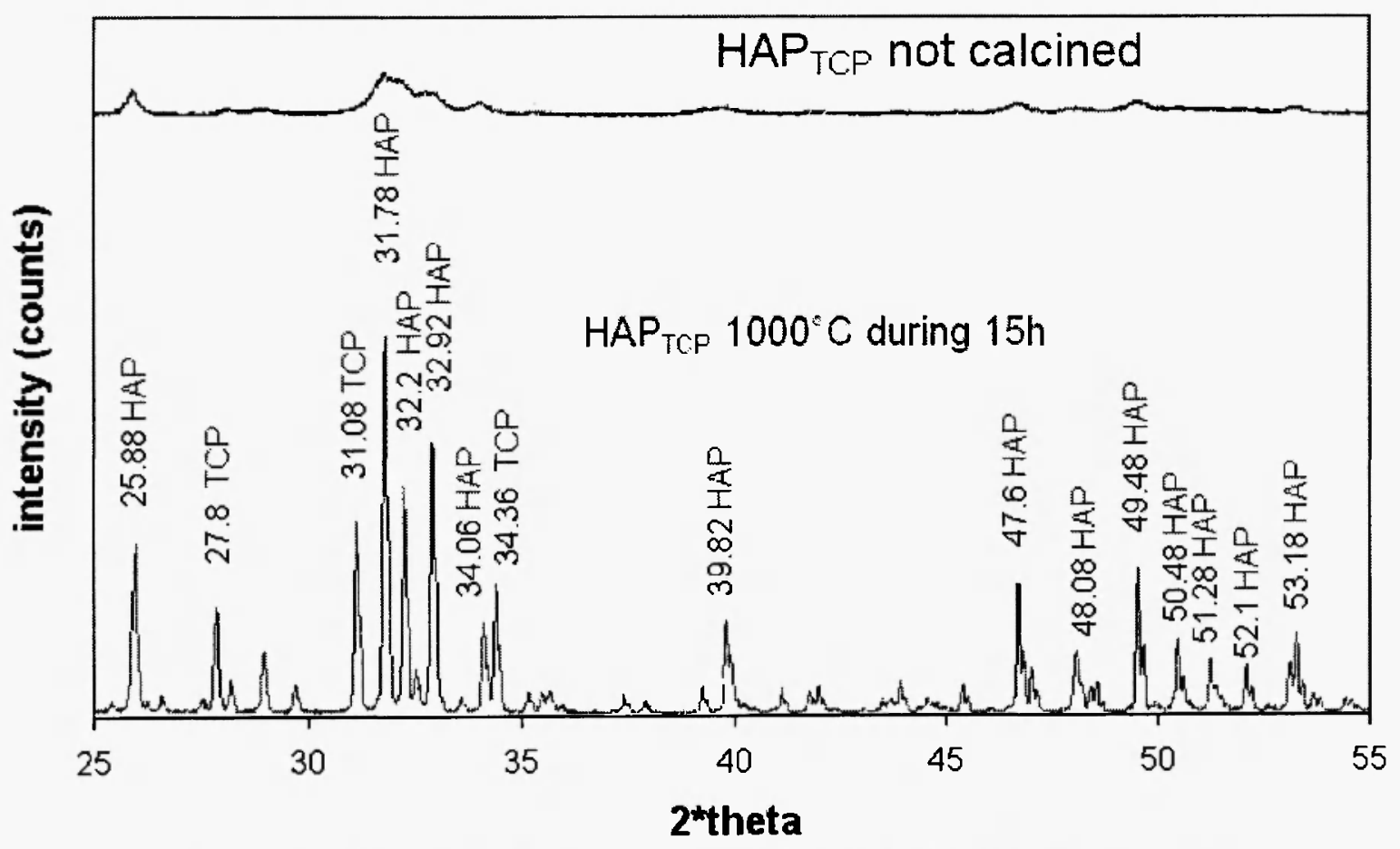

Fig. 2: XRD pattern of $\mathrm{HAP}_{\mathrm{TCP}}$ not calcined and calcined at $1000^{\circ} \mathrm{C}$ during $15 \mathrm{~h}$. 


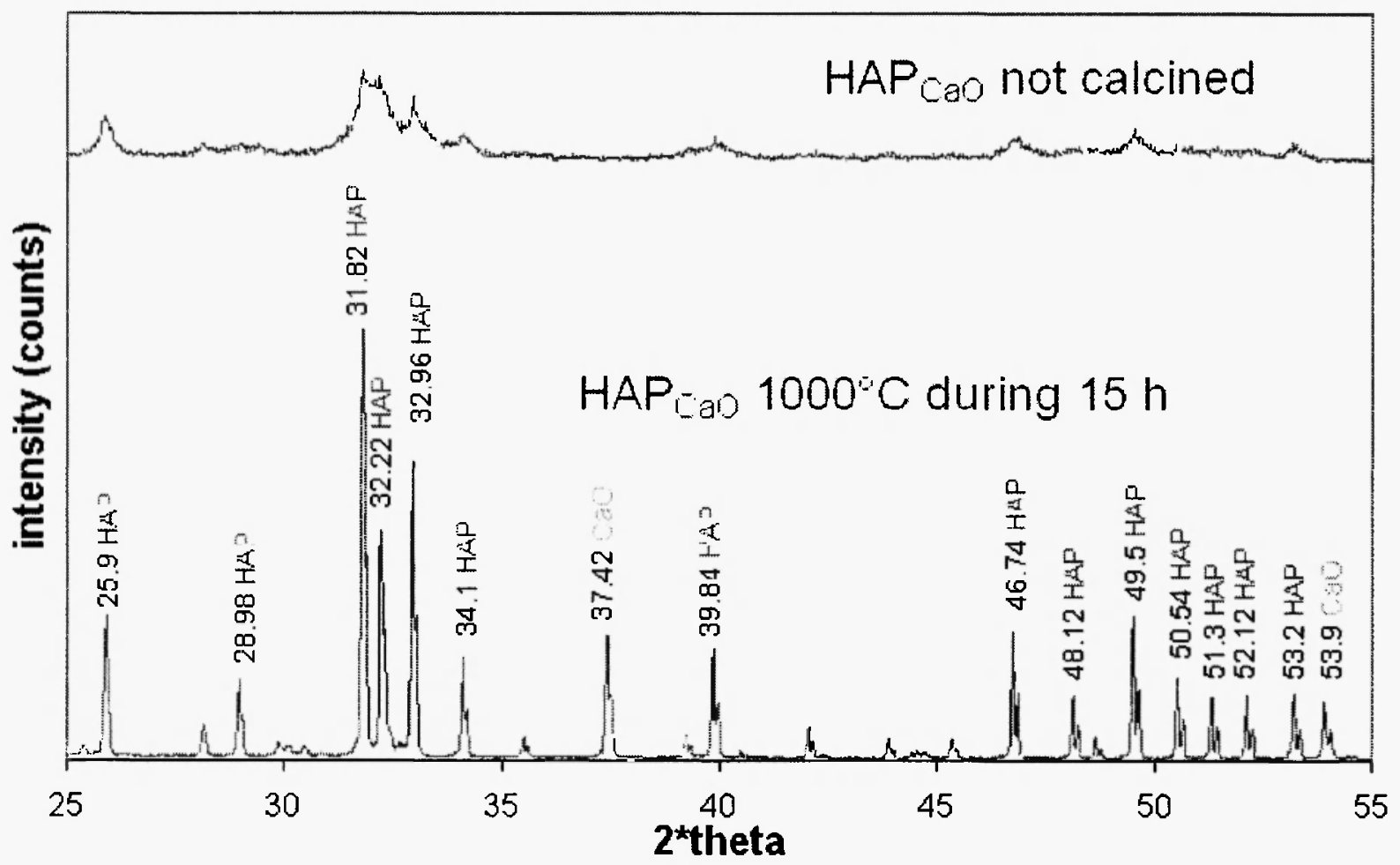

Fig. 3: XRD pattern of $\mathrm{HAP}_{\mathrm{CaO}}$ not calcined and calcined at $1000^{\circ} \mathrm{C}$ during $15 \mathrm{~h}$.

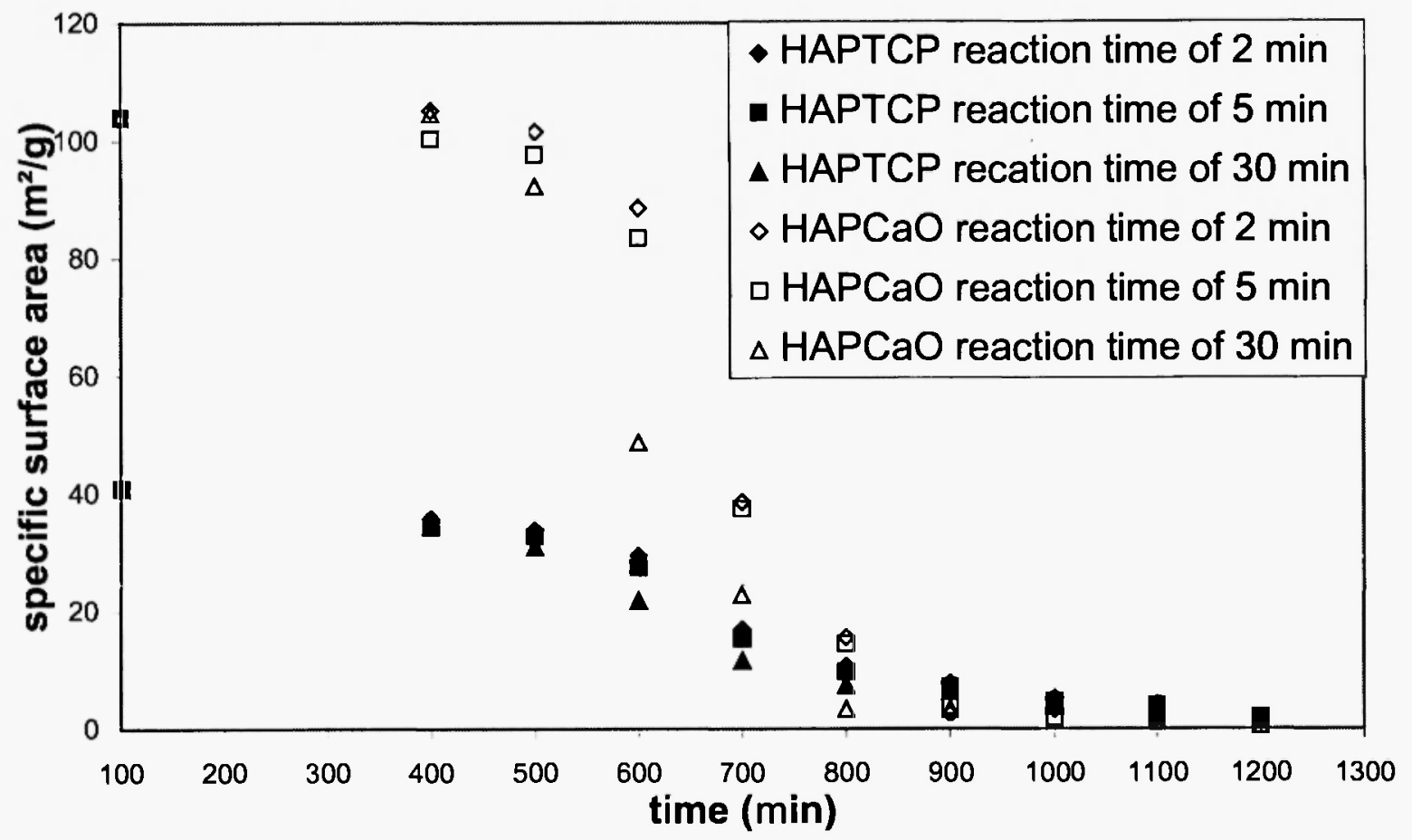

Fig. 4: Specific surface area curves of $\mathrm{HAP}_{\mathrm{TCP}}$ and $\mathrm{HAP}_{\mathrm{CaO}_{\mathrm{O}}}$ during isothermal runs. 
Table 2

Specific surface area models used

\begin{tabular}{|c|c|c|c|}
\hline & $\operatorname{rman} / 35 /$ & Nicholson $/ 28 /$ & Schlaffler $/ 32 /$ \\
\hline$\left.\frac{S_{0}-S}{S_{0}}\right)$ & $=K(T) t$ & $\frac{d S}{d t}=-k_{2}(T)\left(S-S_{f}\right)$ & $\frac{d S}{d t}=-B^{\prime}(T) S^{b}$ \\
\hline
\end{tabular}

surface area So is assumed to be $107 \mathrm{~m}^{2} / \mathrm{g}_{\text {for }} \mathrm{HAP}_{\mathrm{CaO}}$ and $40 \mathrm{~m}^{2} / \mathrm{g}$ for $\mathrm{HAP}_{\mathrm{TCP}}$. The surface area of the product shell is calculated by summation over all the layers and compared with experimental data. The required initial condition is the initial specific surface area and the temperature range. The results obtained are compared in figure 5 for $\mathrm{HAP}_{\mathrm{TCP}}$ and in figure 6 for $\mathrm{HAP}_{\mathrm{CaO}}$.

Figures 5 and 6 show that the Nicholson equation does not fit the experimental data well for the two hydroxyapatites. The values derived for the $\mathrm{n}$ and $\mathrm{y}$ exponent parameters were used to choose the best model. Indeed, y values more than 50 were found for the two hydroxyapatites, which is not realistic. For the Schlaffler model, the values of the constant $b$ of Eq. (4) which vary from 3 to 10 with changing temperature for the two hydroxyapatites are in good agreement with those found in the literature. The value of $b$ decreases regularly from 10 to 3 from 500 to $1200^{\circ} \mathrm{C}$. The changing value of $b$, which is the order of the reaction, suggests that the mechanism of surface area reduction, which was identified as a diffusion mechanism, may be changing with temperature $129,35,36 /$. The Schlaffler model (Eq. (4) was chosen to fit the specific surface area data). This model appears to have considerable merit in determining the dominant mass transport mechanism during the sintering. The assumption that the surface energy provides the driving force for sintering has led to proposals for kinetic laws represented by Eq. (4). This empirical model is in agreement with the specific surface area changes for many systems over time periods during initial, intermediate and final sintering stages.

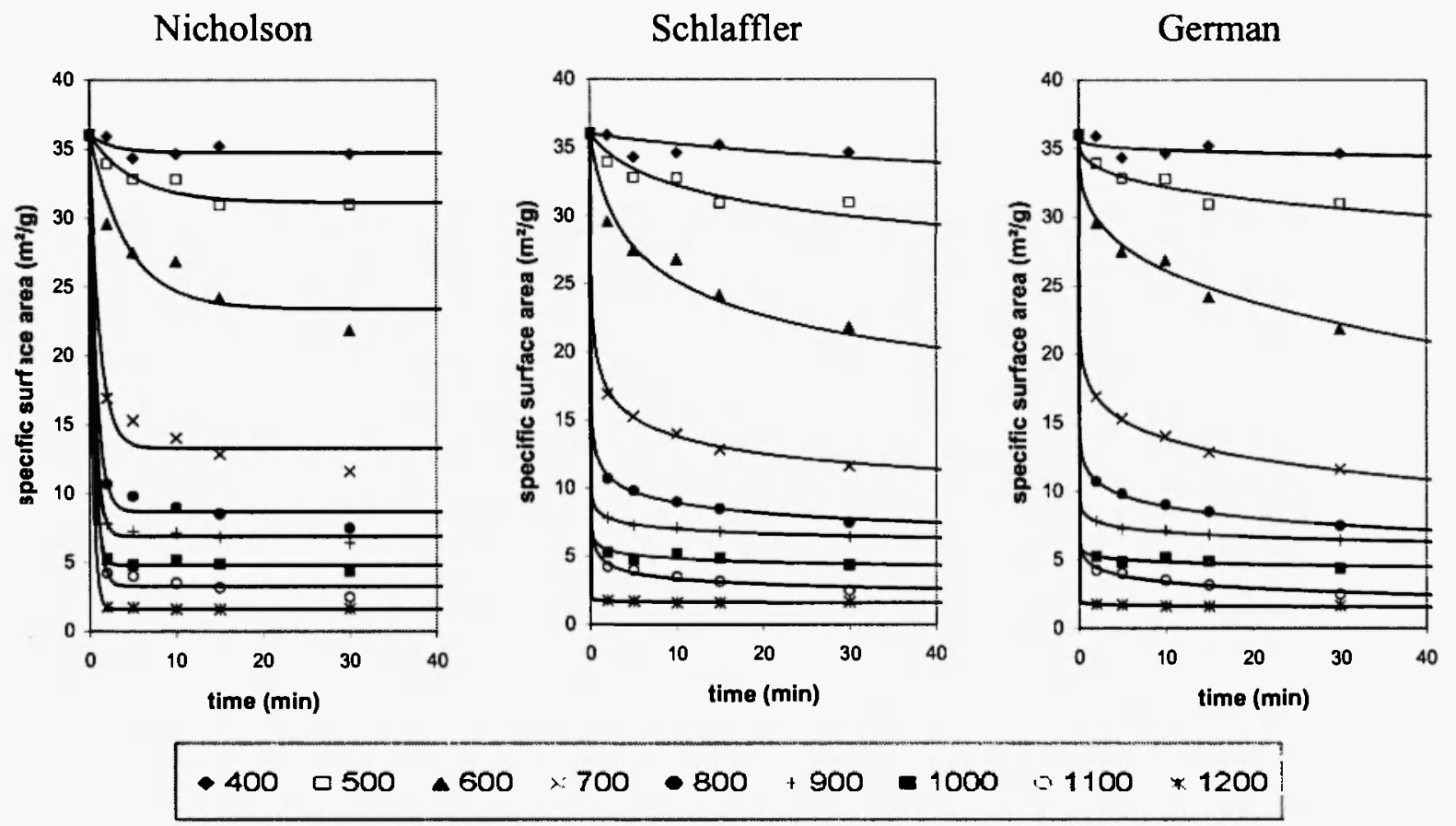

Fig. 5: Modeling of experimental data of surface reduction for $\mathrm{HAP}_{\mathrm{TCP}}$. 


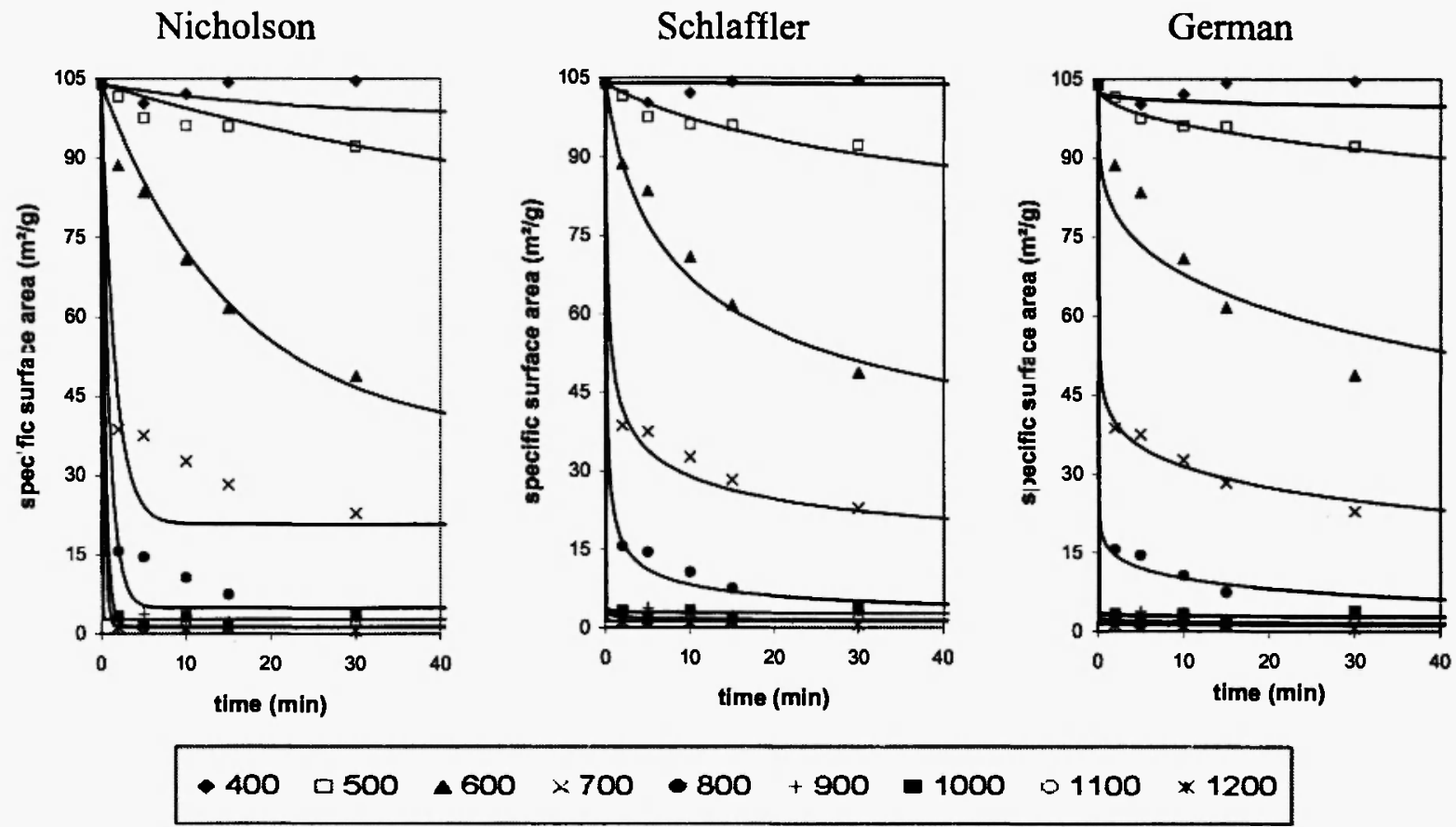

Fig. 6: Modeling of experimental data of surface reduction for $\mathrm{HAP}_{\mathrm{CaO}_{\mathrm{O}} \text {. }}$

In the Schlaffler model, the constant rate $B^{\prime}(T)$ expressed the temperature dependence of the specific surface area. This dependence was determined using the Arrhenius equation indicated by equation (9).

$$
B(T)=k_{0} e^{-E_{a} / R T}
$$

The activation energy, $E_{a}$, of sintering was then deduced (Fig. 7). The values of $248 \mathrm{~kJ} / \mathrm{mol}$ for $\mathrm{HAP}_{\text {TCP }}$ and $480 \mathrm{KJ} / \mathrm{mol}$ for $\mathrm{HAP}_{\mathrm{CaO}}$ are in good agreement with the value of 250 to $500 \mathrm{~kJ} / \mathrm{mol}$ reported by Raynaud $e t$ al. /37,38/ for stoichiometric and non-stoichiometric hydroxyapatites. The activation energy is then the energy that is necessary for the grain growth.

The values of the rate constant and for the reaction order deduced from Eq.(4) are presented in Table 3.

The rate constant, $B^{\prime}(T)$, varies swiftly in the temperature range from $600^{\circ} \mathrm{C}$ to $900^{\circ} \mathrm{C}$ where sintering is observed. This shows the powerful accelerating effect of temperature for the decline of surface area.

For $\mathrm{HAP}_{\mathrm{TCP}}$ the values of $\mathrm{b}$ under $900^{\circ} \mathrm{C}$ increase abnormally, for $\mathrm{HAP}_{\mathrm{CaO}}$ the very high values of $\mathrm{b}$ are obtained at the higher of these temperatures $\left(>900^{\circ} \mathrm{C}\right)$.
For the two hydroxyapatites, it corresponds to the area where the surface is minimum and no sintering is observed.

\section{Possible mechanism of surface reduction}

Identification of the rate-controlling sintering process through the kinetics of surface area reduction involves a number of assumptions. For the model use, the particles are assumed to be monodisperse spheres. Large deviations in either particle shape or size distribution, which are probable, produce unexpected effects not accounted for by the model. The process of fillet formation is believed to be important since it provides the necessary bridges between the particles for subsequent material transport by surface migration, volume diffusion, or viscous flow and also contributes also to the mechanical strength of the aggregate.

The second results should be the disappearance of the smallest particles in the system and the growth of larger ones. This may occur either through the growth of larger particles already present at the expense of the smaller ones, or by the coalescence of several small 


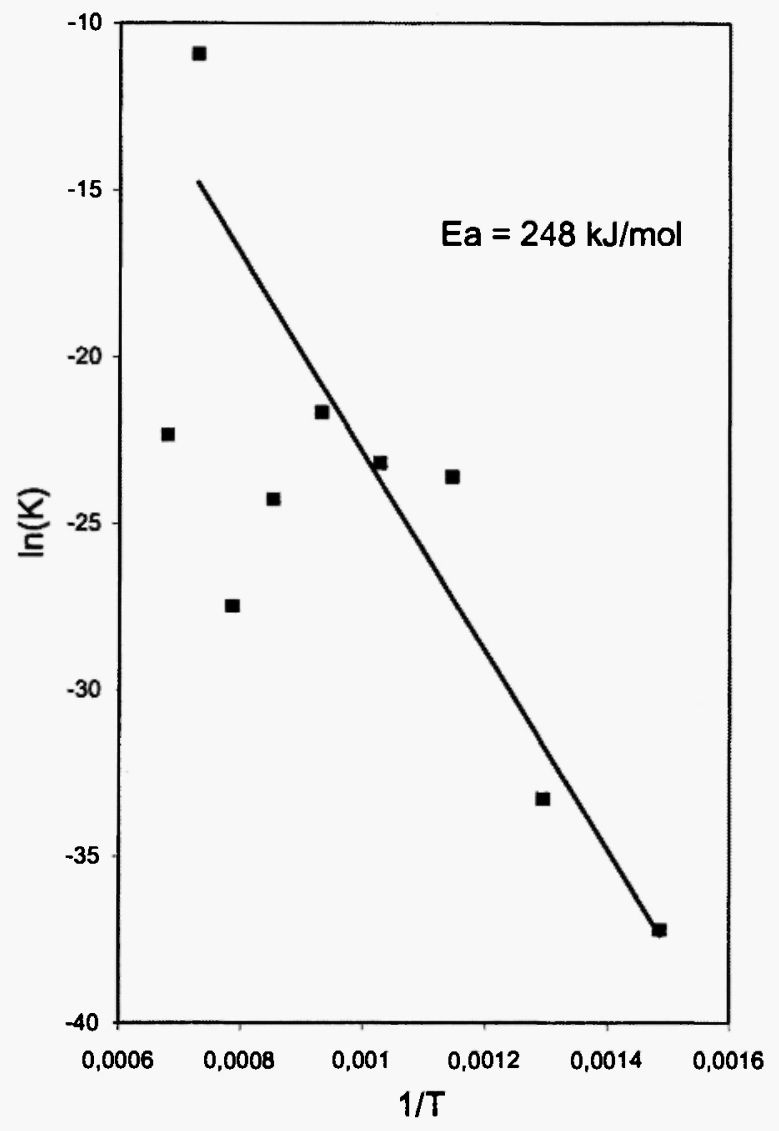

HAP $_{\text {TCP }}$

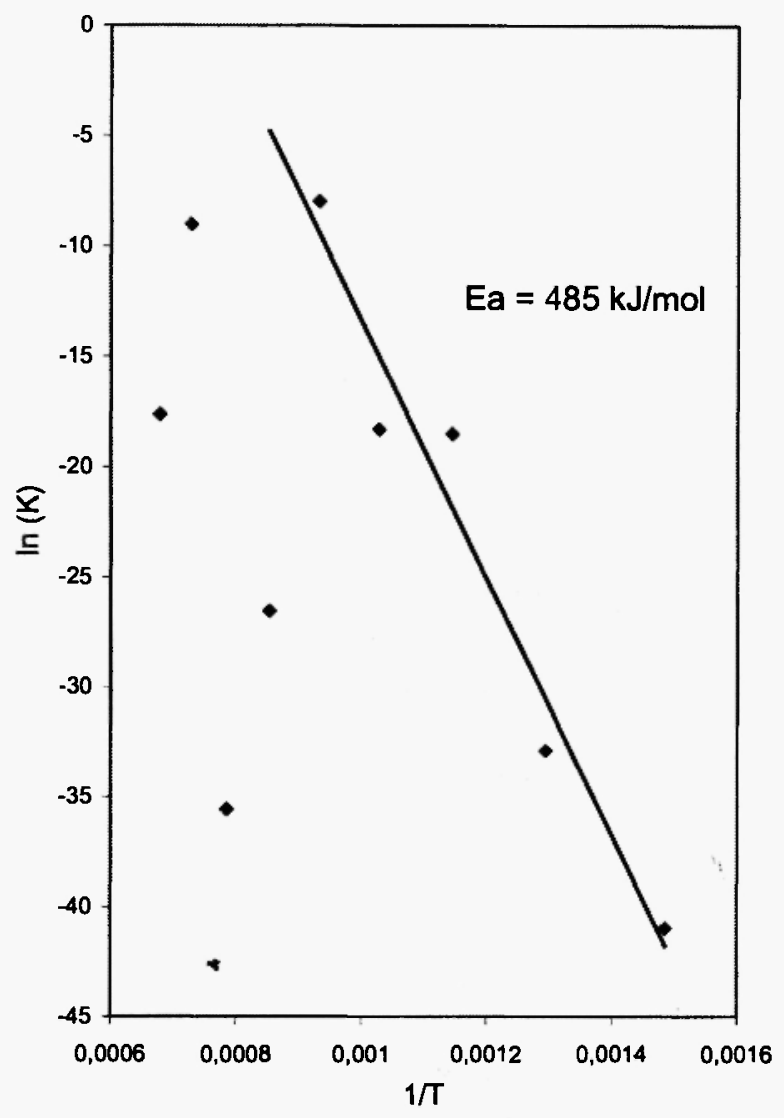

$\mathrm{HAP}_{\mathrm{CaO}}$

Fig. 7: Activation energy of sintering processes for $\mathrm{HAP}_{\mathrm{TCP}}$ and for $\mathrm{HAP}_{\mathrm{CaO}}$.

Table 3

Rate constants and reaction order derived from equation $\frac{d S}{d t}=-B^{\prime}(T) S^{b}$

\begin{tabular}{|c|c|c|c|c|c|c|c|c|c|}
\hline Temperature & 400 & 500 & 600 & 700 & 800 & 900 & 1000 & 1100 & 1200 \\
\hline \multicolumn{10}{|c|}{ HAP $_{\text {TCP }}$} \\
\hline b & 9.7 & 9.1 & 6.9 & 8.2 & 8.9 & 11.2 & 15.3 & 6.7 & 34.1 \\
\hline $\begin{array}{c}B^{\prime}(\mathrm{T}) \\
{\left[\left(\mathrm{m}^{2} / \mathrm{g}\right)^{1-b} \cdot \mathrm{min}^{-1} \mid\right.}\end{array}$ & $6.9010^{-17}$ & $3.5510^{.15}$ & $5.6810^{-11}$ & $8.5410^{-11}$ & $3.8610^{-10}$ & $2.8810^{-9}$ & $1.1510^{-12}$ & $1.7910^{-05}$ & $1.9610^{-10}$ \\
\hline \multicolumn{10}{|c|}{ HAP $_{\mathrm{C}_{\mathrm{O}} \mathrm{O}}$} \\
\hline b & 8.1 & 6.9 & 4.5 & 5.3 & 3.3 & 20.6 & 29.0 & 9.3 & 50.7 \\
\hline $\begin{array}{c}B^{\prime}(T) \\
{\left[\left(\mathrm{m}^{2} / \mathrm{g}\right)^{1-b} \cdot \mathrm{min}^{-1}\right]}\end{array}$ & $1.6110^{-18}$ & $5.1610^{-15}$ & $9.2410^{-09}$ & $1.1410^{-08}$ & $3.4010^{-04}$ & $2.9110^{-2}$ & $3.5710^{-16}$ & $1.2110^{-04}$ & $2.1710^{-08}$ \\
\hline
\end{tabular}


particles to form a larger one.

Which of these processes predominates will be determined by the nature of the transport processes involved. The possible processes for material transport are surface migration, volume diffusion, vapor-phase transport, and viscous flow.

The kinetic analysis of Kuczinsky /39/, who studied the growth of fillets between small spherical metal particles and a plane surface of the same metal, has been generalised by Herring $140 /$, who showed by fairly general arguments that at a given temperature and with a given mechanism for material transport the time required for the average particle size in an aggregate to increase by a constant factor should vary as $r_{0}^{p}$ where $r_{0}$ is a measure of the initial average diameter of the particles in the aggregate. This was demonstrated only for the case where all the aggregates considered have the same packing and particle size distributions and shapes, so that they differ only in the magnitude of $r_{0}$. The power $p$ was shown to depend on the mechanism of material transport (Table 4) and to have the following values: for surface migration, $p=4$; for volume diffusion, $\mathrm{p}=3$; for vapor phase transport, $\mathrm{p}=2$; for viscous (Newtonian) flow, $p=1$. These conclusions are consistent with the empirical law $d S / d t=-B^{\prime}(T) S^{b}$. The values of $b$ found empirically in our experiments increase with the calcination temperature as shown in Fig. 8. The change in slope observed from $800^{\circ} \mathrm{C}$ to $900^{\circ} \mathrm{C}$ corresponds to the end of the sintering for these two HAPs. The values of the reaction order we obtained are considerably larger than the values predicted by Herring.

It is shown readily that the relation between the exponent $b$ of our empirical rate equation and the exponent $p$ of Herring's analysis is $b=p+1$ for a given process of material. Thus the largest value of $b$ predicted by Herring's analysis is 5 .

Schlaffler et al. /32/ and Caillet and Harrison /29/ have also found for exponent $b$ larger values than those predicted by Herring's analysis. In fact the value reported by these authors when using a power law equation to describe the surface area variation of silicaalumina catalysts in steam at temperatures from $478^{\circ} \mathrm{C}$ to $863^{\circ} \mathrm{C}$ ranged from 9.1 at the lower temperature to 3.8 at the higher.

We believe that the larger values of $b$ observed at the lower temperatures and at higher temperatures $\left(>900^{\circ} \mathrm{C}\right)$ can be accounted for by a vapor phase transport process involving the formation of volatile species like water in the case of $\mathrm{HAP}_{\mathrm{CaO}}$ where the decomposition of the excess of $\mathrm{Ca}(\mathrm{OH})_{2}$ to $\mathrm{CaO}$ was observed. This observation is confirmed by the value of the reaction order $b=\mathbf{3}$ which can be attributed to vapor phase transport of water of decomposition of $\mathrm{Ca}(\mathrm{OH})_{2}$. In the sintering temperature domain from $600^{\circ} \mathrm{C}$ to $900^{\circ} \mathrm{C}$, the values of $\mathrm{b}$ are consistent, in the light of Herring's analysis, with a predominance of processes such as surface migration and volume diffusion as shown in Fig. 9. Such a change in the relative importance of various mechanisms of material transport with changing temperature would be expected $a$ priori since the different mechanisms should have different activation energies in both cases, as shown in Fig. 7 where the slope change is observed in both cases under $900^{\circ} \mathrm{C}$.

Another interpretation of these observations will be proposed later in this paragraph. However, only the value bounded from $250 \mathrm{~kJ} / \mathrm{mol}$ to $500 \mathrm{~kJ} / \mathrm{mol}$ is reported in the literature for the sintering of hydroxyapatite $137,38 \%$. In fact, the low activation

Table 4

Principal mechanism of material transport from Fig. 9

\begin{tabular}{|c|c|c|c|c|}
\hline $\begin{array}{c}\text { Number } \\
\text { mark }\end{array}$ & $\begin{array}{c}\text { Source of } \\
\text { matter }\end{array}$ & $\begin{array}{c}\text { Destination of } \\
\text { matter }\end{array}$ & $\begin{array}{c}\text { Reaction order } \\
b=p+1\end{array}$ & Mechanism by Herring \\
\hline 1 & Surface of grain & Surface of grain & 5 & Surface migration \\
\hline 7 & Grain boundary & Volume of grain & 4 & Volume diffusion \\
\hline 3 & Surface of grain & Surface of grain & 3 & Vapor transport \\
\hline 8 & Surface of grain & Volume of grain & 2 & Viscous flow \\
\hline
\end{tabular}




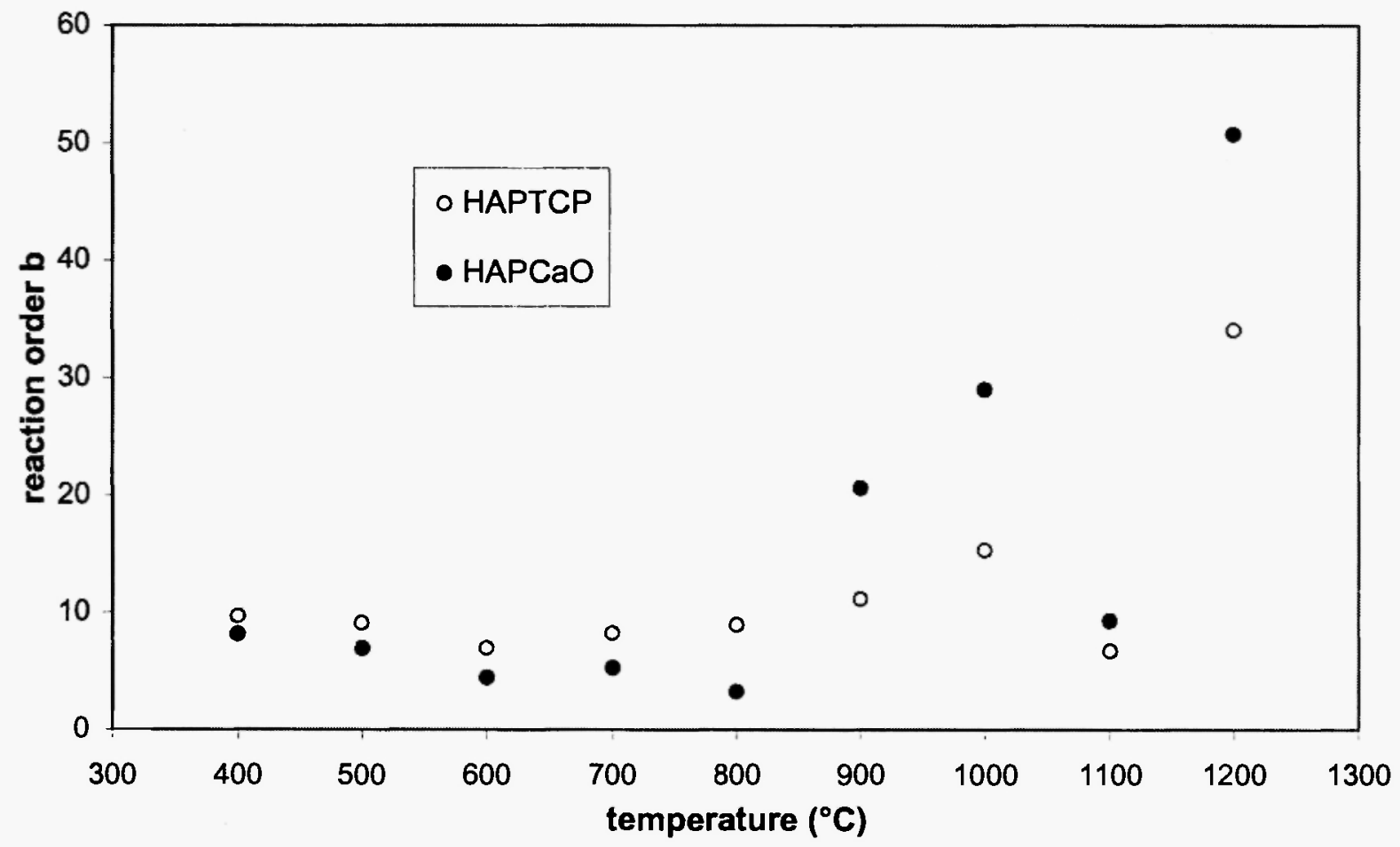

Fig. 8: Effect of the calcination temperature on the reaction order.

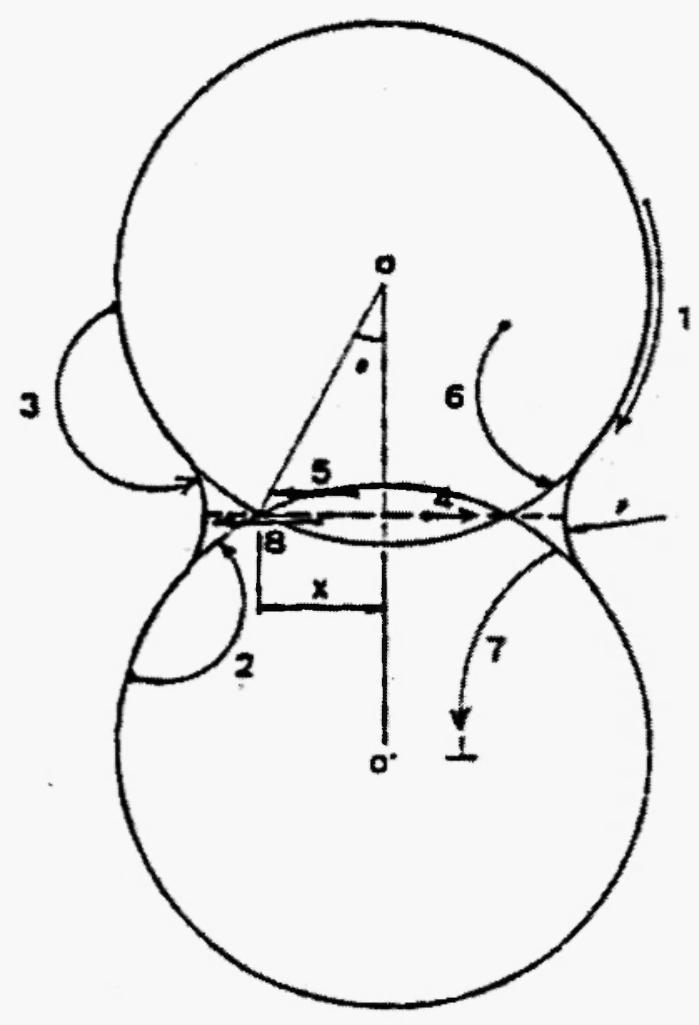

Fig. 9: Possible mechanism of surface reduction. energy under $900^{\circ} \mathrm{C}$ can be attributed to particle dilatation due to the heating and for the temperature greater than $900^{\circ} \mathrm{C}$. the partially decomposition of HAP into tetracalcium phosphate $\left(\mathrm{Ca}_{4}\left(\mathrm{PO}_{4}\right)_{2} \mathrm{O}, T T C P\right)$ and a tricalcium phosphate $\left(\mathrm{Ca}_{3}\left(\mathrm{PO}_{4}\right)_{2}, \alpha-T C P\right)$ is observed. That induces the change in mechanism observed and then in activation energy. Therefore, the ACP that was heated over a temperature range of $600^{\circ} \mathrm{C}-1200^{\circ} \mathrm{C}$ formed mainly an HAP phase. Similar results were reported by Layrolle et al. $141 \%$.

If the surface area reduction process observed from $600^{\circ} \mathrm{C}$ to $900^{\circ} \mathrm{C}$ is controlled only by the surface migration and the volume diffusion, we can suppose that in this temperature range the reaction order $b$ can be considered constant. Then Eq. (4) is solved with constant exponents which are $b=4$ and $b=5$ for surface migration and volume diffusion control of the surface area reduction referring to Herring's analysis. We also consider the exponent $b=7$ and 8 for $\mathrm{HAP}_{\mathrm{TCP}}$ and from 3 to 7 for $\mathrm{HAP}_{\mathrm{CaO}}$ referring to the results of Table 3 . The activation energy is deduced using the Arrhenius plot of Fig. 10 for the two HAPs, and presented in Table 5.

In comparison with the literature results for sintering 


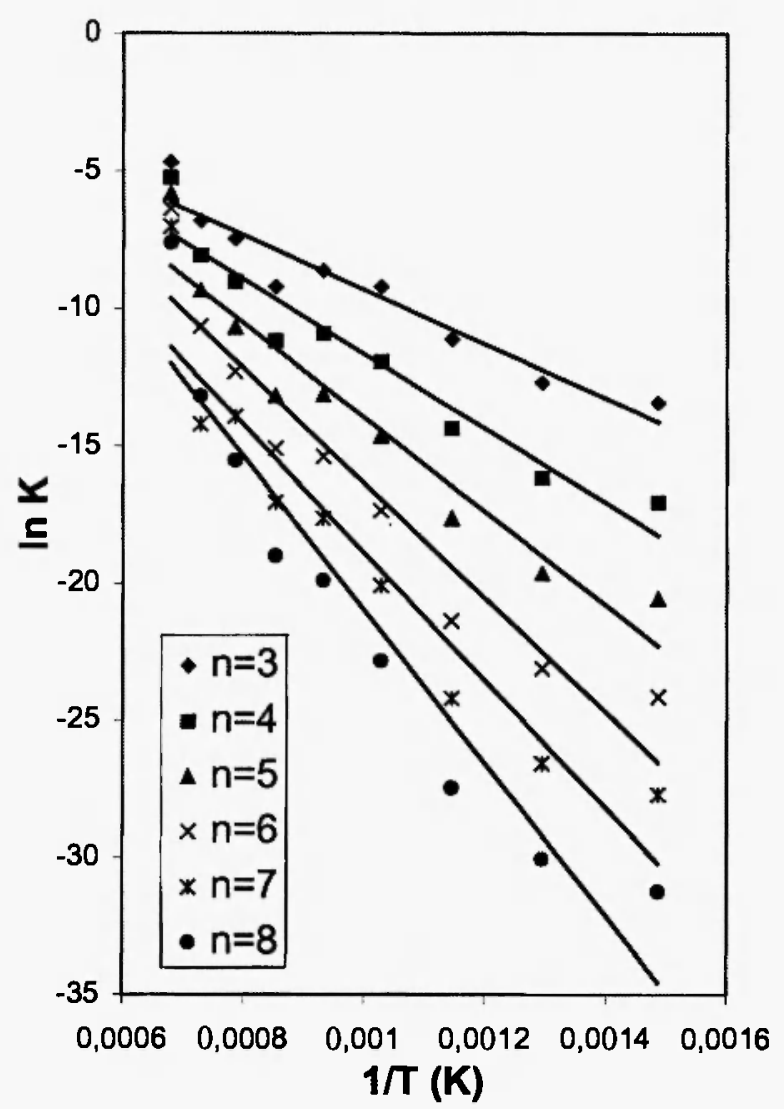

$\mathrm{HAP}_{\mathrm{TCP}}$

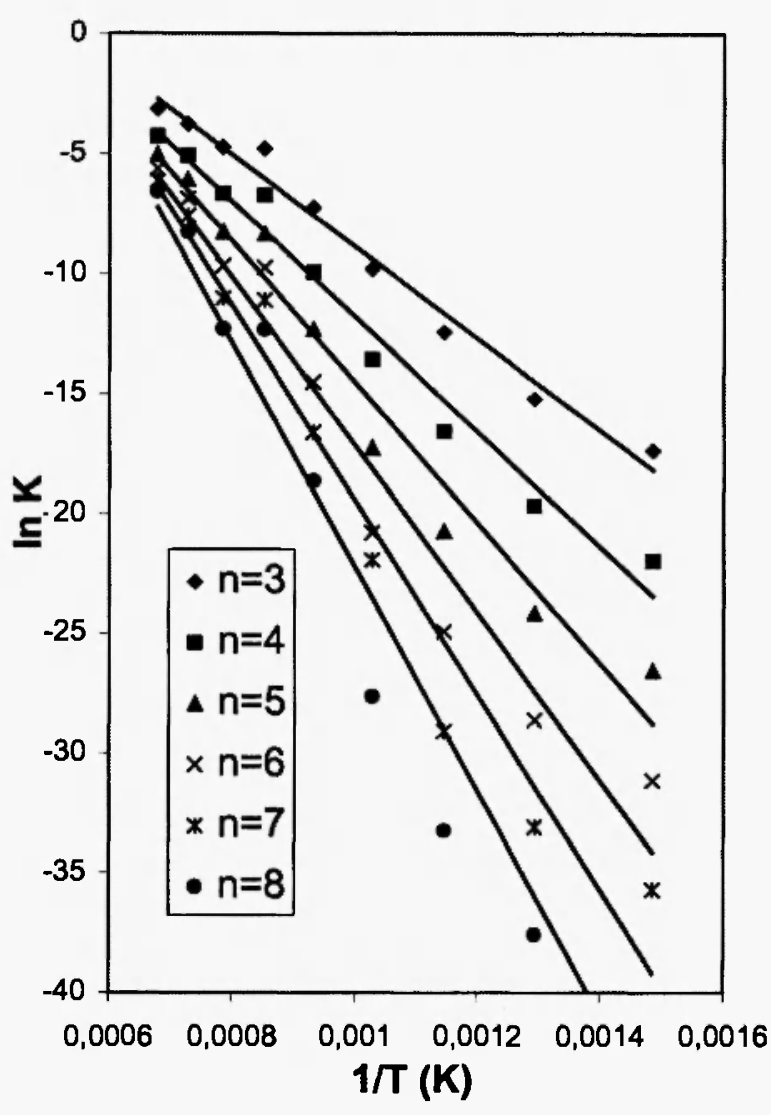

$\mathrm{HAP}_{\mathrm{CaO}}$

Fig. 10: Activation energy of surface area reduction versus the reaction order.

Table 5

Activation energies for fixed reaction order

\begin{tabular}{|c|c|c|c|c|c|c|c|}
\hline \multicolumn{2}{|c|}{$b$} & 3 & 4 & 5 & 6 & 7 & 8 \\
\hline \multirow{2}{*}{$\begin{array}{c}\mathrm{Ea} \\
\mathrm{kJ} / \mathrm{mol}\end{array}$} & $\mathrm{HAP}_{\mathrm{TCP}}$ & 104 & 126 & 152 & 179 & 200 & 226 \\
\cline { 2 - 8 } & $\mathrm{HAP}_{\mathrm{CaO}}$ & 159 & 199 & 244 & 290 & 338 & 388 \\
\hline
\end{tabular}

of HAP $/ 37,38 /$ and with the results we presented in Fig. 7 where $b$ depends on the temperature, we can observe that using the Herring's analysis of the processes involved ( $b=4$ and 5 ), the activation energy is lower than that published for HAP. However with our results (Fig. 7) considering only surface migration (grain boundary diffusion) and volume diffusion, then driving forces of surface reduction with reaction order from the activation energy obtained (Table 5: $>200$ $\mathrm{kJ} / \mathrm{mol}$ for $\mathrm{HAP}_{\mathrm{TCP}}$ and $>300 \mathrm{~kJ} / \mathrm{mol}$ for $\mathrm{HAP}_{\mathrm{CaO}}$ ) are in the same range as that obtained by considering the variation of $b$ with the temperature (Fig.7: $248 \mathrm{~kJ} / \mathrm{mol}$ for $\mathrm{HAP}_{\mathrm{TCP}}$ and from 250 to $500 \mathrm{~kJ} / \mathrm{mol}$ for $\mathrm{HAP}_{\mathrm{TCAO}}$ ). The surface migration and volume diffusion suggest that the elimination of pores in a powder system is achieved only when the grain boundaries are present. In the grain boundary diffusion, a pore may be considered as consisting of vacancies, which dissolve in the grain boundaries ending at the pore and are replaced by atoms from the boundaries. Dissolved vacancies are swiftly 
transmitted to the surface of grain by vacancy-grain diffusion, and in turn replaced by atoms from the surrounding particles. In volume diffusion as in the case of "neck" formation discussed in the introduction, the grain surrounding a void of defined radius will contain an excess concentration of vacancies expressed by Eq. (10).

$$
\Delta C=\frac{\gamma \delta^{3} C_{0}}{k T r}
$$

where $\gamma$ is the surface tension, $\delta$ the interatomic distance, $k$ the Boltzmann's constant, $T$ the temperature, and $\mathrm{C}_{0}$ the equilibrium concentration of vacancies underneath a flat surface.

There exists a gradient of vacancy concentration of the order of magnitude of $\Delta \mathrm{C} / \mathrm{r}$. Under a steady-state condition, these vacancies migrate towards the nearest sinks provided by the grain boundaries, and are continuously replaced by vacancies from the pore. As soon as the vacancies reach a grain boundary, they are swiftly rempved by vacancy-grain boundary diffusion to the surface of large radii of curvature, such as the surface of the particle $/ 42 /$.

\section{CONCLUSION}

The behaviour during calcination of two macroporous and non-stoichiometric hydroxyapatites (calcium deficient and calcium excess) was investigated. In both cases, the crystallisation of the initial amorphous calcium phosphate (ACP) structure and a significant decrease of the specific surface area was observed versus the temperature. This study confirms that sintering of $\mathrm{ACP}$ powder occurs during calcination. After heating at $600^{\circ} \mathrm{C}$, the $\mathrm{ACP}$ particles crystallise to an HAP phase. The hydroxyapatite sintering begins near $600^{\circ} \mathrm{C}$ and reaches the maximum near $900^{\circ} \mathrm{C}-1000^{\circ} \mathrm{C}$. The kinetics of this sintering process was investigated in terms of specific surface area reduction. The Schlaffler model appears to help to understand the dominant mass transport mechanism during sintering. The mechanism of the sintering is discussed in terms of the variation of the order or the reaction $b$ and the activation energy. The variation observed suggests that the mechanism for loss of surface area which was supposed than surface and volume diffusion mechanisms may change with temperature. For $\mathrm{HAP}_{\mathrm{CaO}}$, the vapor phase transport can also be considered due to the decomposition of excess of $\mathrm{Ca}(\mathrm{OH})_{2}$ to $\mathrm{CaO}$. Thermal crystallisation is accompanied by active surface and volume diffusion within the initial particles, which constitutes the driving force for the sintering process.

\section{ACKNOWLEDGEMENTS}

The authors thank Prof. Didier Bernache-Assolant, Prof. Patrick Sharrock and Dr. Eric Champion for helpful discussions.

\section{REFERENCES}

1. Q.Y. Ma, S.J. Traina, T.J. Logan and J.A. Ryan, Environ. Sci. Technol., 27, 1803 (1993).

2. T. Suzuki, T. Hatsushika and M. Miyake, J. Chem. Soc., Faraday Trans. 1, 78, 3605 (1982).

3. Y. Takeuchi and H. Arai, J. Chem. Eng. Jpn., 23, 75 (1990).

4. Q.Y. Ma, S.J. Traina, T.J. Logan and J.A. Ryan, Environ. Sci. Technol., 28, 1219 (1994).

5. Q.Y.Ma, T.J. Logan, S.J. Traina and J.A. Ryan, Environ. Sci. Technol., 28, 408 (1994).

6. N.C.C. da Rocha, R.C. de Campos, A.M. Rossi, E.L. Moreira, A.F. Barbosa and G.T. Moure, Environ. Sci. Technol., 36, 1630 (2002).

7. J.C. Elliot, Structure and Chemistry of the Apatites and Other Calcium Orthophosphates, Amsterdam, The Netherlands, Elsevier Science B.V., 1994.

8. T.S.B. Narasaraju and D.E. Phebe, J. Mater. Sci., 31, 1 (1996).

9. Q.Y.Ma, S.J. Traina, T.J. Logan and J.A. Ryan, Environ. Sci. Technol., 27, 1803 (1993).

10. V. Laperche, S.J. Traina, P. Gaddam and T.J. Logan, Environ. Sci. Technol., 30, 3321 (1996).

11. S. Bailliez, A. Nzihou, P. Sharrock, Proceedings of the $6^{\prime \prime}$ World Congress of Chemical Engineering, (Melbourne, Australia, 2001), 1228, $1-10$. 
12. S. Iretskaya, A. Nzihou, C. Zahraoui and P. Sharrock, Environmental Progress, 18, 144 (1999).

13. A. Nzihou and P. Sharrock, Waste Management, 22, 235 (2002).

14. G.C. Kuczynski, Trans. AIME, 185, 169 (1949).

15. W.D. Kingery and M. Berg, J. Appl. Phys., 26, 1205 (1955).

16. J.E. Burke, J. Am. Ceram. Soc., 40, 80 (1957).

17. R.L. Coble, J. Am. Ceram. Soc., 41, 55 (1958).

18. R.L. Coble, J. Appl. Phys., 32, 787 (1961).

19. M.F. Ashby, Acta Metall., 22, 275 (1974).

20. F.B. Swinkels and M.F. Ashby, Acta Metall., 29, 259 (1981).

21. A.S. Helle, K.E. Easterling and M.F. Ashby, Acta Metall, 33, 2163 (1985).

22. E. Arzt, Acta Metall., 30, 1883 (1982).

23. J.D. Hansen, R.P. Rusin, M.H. Teng and D.L. Johnson, J. Am. Ceram. Soc., 75, 1129 (1992).

24. D.L. Johnson, J. Appl. Phys., 40, 192 (1969).

25. J. Wang and R. Raj, J. Am. Ceram. Soc., 73, 1172 (1990).

26. J. Zhao and M.P. Harmer, Philos. Mag Lett., 63, 7 (1991).

27. M.-Y. Chu, M.N. Rahaman, L.C. de Jonghe and R.J. Brook, J. Am. Ceram. Soc., 74, 1217 (1991).

28. D. Nicholson, Trans. Faraday Soc., 61, 990
(1965).

29. D.A. Caillet and D.P. Harrisson, Chem. Eng. Sci., 37, 625 (1982).

30. P.V. Ranade and D.P. Harrison, Chem. Eng. Sci., 34, 427 (1979).

31. R.M. German, J. Am. Ceram. Soc., 61, 272 (1978).

32. W.G. Schaffler, C.Z. Morgan and J.N. Wilson, J. Phys. Chem., 61, 714 (1957).

33. S. Bailliez and A. Nzihou, Proceedings of the $4^{\text {th }}$ World Congress on Particle Technology, July 2225, 2002, Sydney, Australia, 263.

34. AFNOR Standard NF S 94-066 (1998).

35. R.M. German and Z.A. Munir, J. Am. Ceram. Soc., 59, 379 (1976).

36. G.C. Kuczynski, Metals Transactions, 1949, 169.

37. S. Raynaud, E. Champion and D. BernacheAssolant, Biomaterials, 23, 1073 (2002).

38. A. Ababou, Etude experimentale et theorique du préfrittage et du frittage de l'hydroxyapatite $\mathrm{Ca}_{10}\left(\mathrm{PO} \mathrm{O}_{6}\right)_{6}(\mathrm{OH})_{2}$, Ph. D. Thesis dissertation, Université de Limoges-France, juin 1994.

39. G.C. Kuczinski, J. Metals, 1, 169 (1949).

40. C. Herring, J. Appl. Phys., 21, 301 (1950).

41. P. Layrolle, A. Ito and T. Tateishi, J. Am. Ceram. Soc., 81, 1421 (1998).

42. G.C. Kuczinski, Acta Metallurgica, 4, 58 (1956). 
